\title{
Epidemiology of Suicide and its Associated Socio-demographic Factors in Patients Admitted to Emergency Department of Zahedan Khatam-Al-Anbia Hospital
}

\author{
Fatemeh Behmanehsh Pour ${ }^{1}$; Seyed Mehdi Tabatabaei ${ }^{2,} ;$ Nour-Mohammad Bakhshani $^{3}$

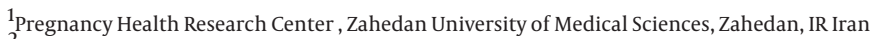 \\ ${ }^{2}$ Health Promotion Research Center, Zahedan University of Medical Sciences, Zahedan, IR Iran \\ ${ }^{3}$ Children and Adolescent Health Research Center, Department of Clinical Psychology, Zahedan University of Medical Sciences, Zahedan, IR Iran \\ ${ }^{*}$ Corresponding author: Seyed Mehdi Tabatabaei, Health Promotion Research Center, Zahedan University of Medical Sciences, Zahedan, IR Iran. Tel: +98-541-2438801, Fax: +98-541- \\ 2438800, E-mail: zu.healthdeputy@gmail.com
}

Received: August 8, 2014; Revised: August 14, 2014; Accepted: August 15, 2014

\begin{abstract}
Background:Suicide is a growing public health problem all over the world. Understanding the prevalence of suicide and its correlates is of great importance in planning programs to reduce the risk in different societies.

Objectives:The present study was conducted to assess the epidemiology of suicide and its associated risk factors in Sistanand Balouchestan Province, southeast of Iran.

Patients and Methods: We investigated a total of 369 suicide cases admitted to the emergency department of Zahedan Khatam-Al-Anbia hospital between March 2010 and February 2012. Data were collected from the hospital information system (HIS) using a semi-structured questionnaire. Descriptive statistics and chi-square tests were used to identify the factors associated with suicidal behaviors.

Results: A greater proportion of the study subjects (65\%) were female. They were more likely to be young ( $43.5 \%$ in the age group of 16 to 25 years) and illiterate or have a primary school education (20.9\% and $48.8 \%$, respectively). Housewives and self-employed individuals and those with a low or medium income dominated the suicide cases. The most common method of suicide was burning (53.4\%) followed by drug ingestion (23.8\%). One third of the suicide cases occurred during spring. The case fatality rate was $49.6 \%$ and it was significantly associated with low income, summer time suicides, burning as a method of suicide.

Conclusions: This study highlights the burden of suicide and itspotential socio-demographic risk factors in Sistan and Blouchestan Province. This information has an implication for planning the preventive measures, policy making and future research.
\end{abstract}

Keywords: Suicide, Attempted; Demography; Epidemiology; Iran

\section{Background}

Suicide is an important public health problem both in developing and developed countries, which accounts for more than 80000 annual deaths worldwide (1).In 2008, the suicide rate for the world was reported to be 11.6 per 100,000 population (2). However, the number of suicide cases has been rising and it is predicted to account formore than $2 \%$ of the global burden of disease by the year 2020 (3). This is the case with suicide attempts (SAs) that can be much more frequent and in some studies it has been reported that the prevalence of SAs was 10 to 20 times higher than that of completed suicides (1). The median suicide rate for the countries of the eastern Mediterranean region (EMR) was estimated to be 4.90 per 100000 population, which was lower than the global rate (4).

In a systematic review of studies on suicide and suicide attempts in Iran, the prevalence of suicide was estimated to be 9.4 in 100000, which is much higher than the average prevalence in EMR countries (5). However, there is a great variation in the prevalence of suicide in different parts of the country. For instance, in Hamadan Province, the estimated incidence rate of suicide attempts per 100000 population was 228.6 for males and 263.1 for females (6). An epidemiological survey of the trend of suicide in southwest of Iran between 2004 and 2009 found that the rate of suicide attempt for both genders was 53 per 100000 and 49, 57 for men and women, respectively (7). Moreover, the results of a study on the burden of diseases, injuries, and associated risk factors conducted in 2010 in Iran showed the increasing trends of the major causes of disability-adjusted life years (DALYs) including suicide (8).

More than $90 \%$ of all cases of suicides are attributed to psychological disorders such as depression and substance abuse (1). It has been estimated that $5 \%$ of patients with mood disorders and 6\% of cases with bipolar disorders and possibly a greater proportion of patients with major depressive disorder are likely to commit suicide during their life time (9).

However, there is some evidence that the suicidal acts are a result of an interaction between biological, genetic,

Copyright (C) 2014, Zahedan University of Medical Sciences; Published by Kowsar. This is an open-access article distributed under the terms of the Creative Commons Attribution-NonCommercial 4.0 International License (http://creativecommons.org/licenses/by-nc/4.0/) which permits copy and redistribute the material just in noncommercial usages, provided the original work is properly cited. 
psychological, social, environmental and situational factors (10). Therefore, when investigating the epidemiology of suicide, in addition to the psychological factors, taking into account the influence of other factors, such as the cultural and socio-economic status is of a particular importance (3).

\section{Objectives}

Since the possible factors that contribute to suicidal behavior can greatly vary depending on the characteristics of the population, the objective of this study was to investigate the epidemiology of suicide in Sistan and Baluchestan Province, southeast of Iran, and to identify the precipitating factors in the suicidal behavior. This is of great importance for policy-making and developing the preventive action plans in defined populations and communities.

\section{Patients and Methods}

\subsection{Study Population}

The study population included all suicide cases who were admitted to the emergency department of Zahedan Khatam-Alanbia Hospital between March 2010 and February 2012. This hospital is a referral center for toxicology, burns and other emergency services that admit patients from all the cities in the province. We also included the suicides registered with the Forensic Medicine Department during the same time period.

The information was collected from the hospital information system (HIS), which is used to manage all aspects of hospital operation, such as medical and administrative activities. The Provincial Forensic Medicine Department database was another source of information for retrieving data on suicide cases not available in the hospital HIS.

\subsection{Data Collection}

An 18-item structured questionnaire was used for data collection. The study questionnaire comprised 2 parts: The first 6 questions were related to the socio-demographic characteristics of the subjects such as gender, age, education, occupation, marital status and income. The second part included questions on history of mental and psychological disorders, factors contributing to suicidal acts, the methods used for suicide, substances used for burning, the time and place of suicide, hospitalization and outcome of the suicide attempt.

The tool designed for data collection was developed based on literature review and the questionnaires used in the similar studies conducted in Iran and it was modified according to the study objectives. An expert panel consisting of the psychiatrists, clinical psychologists and experienced nurses assessed the content validity of the questionnaire and necessary changes were made based on the feedback we received. Three trained nurses com- pleted the questionnaires. All completed questionnaires were reviewed by study investigators and ambiguities and gaps in data were queried. Patients and/or their family members were interviewed for the additional information needed.

\subsection{Statistical Analysis}

Categorical variables were presented as counts and percentages. The Chi-square and Fisher's exact tests were used to compare the distribution of categorical variables between different groups. A P $<0.05$ was considered significant for all analyses. Data analysis was performed using SPSS version 20 (Chicago, IL).

\section{Results}

A total of 369 suicide cases, including 240 (65\%) females and 129 (35\%) males were admitted to the emergency department of Zahedan Khatam-Al-Anbia Hospital between March 2010 and February 2012. The demographic characteristics of the participants have been presented in Table 1. The greatest proportion of the cases studied were in the age group of 16 to 25 years (43.5\%) and those aged 34 years and older showed the lowest proportion (i.e. 12.7\%). Patients who finished high school studies and those with a university degree were less likely to attempt or commit suicide (9.5\%) while almost half the cases were found to have a primary school education. Housewives and selfemployed individuals accounted for more than three quarters of the subjects investigated. The majority of suicide patients reported to have a low or medium income and only $16 \%$ were found to have a good income. More than one third of the cases had a history of hospitalization because of mental disorders and $62.9 \%$ were receiving outpatient treatment for psychological problems. A total of 39 cases (10.9\%) were living in Zahedan city and the rest of the subjects were referred from other districts to Zahedan Hospitals. Almost half of the cases were residents of Saravan and Iranshahr districts while those from Zabol and Nikshahr districts accounted for 9.2\% and 9.8\% of the subjects, respectively.

The correlates of the suicidal behaviors have been presented in Table 2 . The most common method of suicide was burning (53.4\%) followed by drug ingestion (23.8\%). Kerosene was the substance commonly used for burning (81.4\%). More than $90 \%$ of burning suicide cases (i.e. 180 patients) were those referred from other districts to the Khatam-Al-Aanbia Hospital. In Zabol, Khash, Saravan and Chabahar, a greater proportion of suicides were by burning, ranging from 53\% to 70\% and in Zahedan, Iranshahr and Nikshahr non-burning methods dominated changing between $22 \%$ and $44 \%$.

The majority of cases attempted suicide at home (88.1\%) followed by relatives' places (8.1\%) and only a small proportion (i.e. 1.4\%) of cases chose public places for suicide attempts. Half of the suicides occurred during the noon time and the cases in the morning and at night accounted 
Table 1. The Socio-Demographic Characteristics of the Suicide Patients Admitted to Zahedan Khatam-Al-Anbia Hospital, 2010$2012(\mathrm{n}=369)^{\mathrm{a}}$

\begin{tabular}{cc}
\hline & Results \\
\hline Gender & \\
Female & $240(65.0)$ \\
\hline Male & $129(35.0)$ \\
\hline Age, $\mathbf{y}$ & \\
$\leq 15$ & $60(16.3)$ \\
$16-25$ & $160(43.4)$ \\
$26-34$ & $102(27.6)$ \\
$>34$ & $47(12.7)$ \\
\hline
\end{tabular}

\section{Education}

$\begin{array}{lc}\text { Illiterate } & 77(20.9) \\ \text { Primary school } & 180(48.7) \\ \text { Guidance and high school } & 77(20.9) \\ \text { Diploma and higher degrees } & 35(9.5)\end{array}$

\section{History of Mental Disorders}

$\begin{array}{lc}\text { Hospitalized } & 41(11.1) \\ \text { Outpatient medication } & 232(62.9) \\ \text { None } & 96(26.0) \\ \text { Income } & \\ \text { Poor } & 113(30.6) \\ \text { Medium } & 197(53.4) \\ \text { Good } & 59(16.0)\end{array}$

\section{Marital Status}

Married

$239(64.8)$

Single

$76(20.6)$

Divorced

$37(10.0)$

Widowed

$17(4.6)$

\section{Occupation}

Housewife

$206(55.8)$

Government job

$32(8.7)$

Self-employed

$82(22.2)$

Unemployed

$49(13.3)$

\section{District}

\begin{tabular}{lc} 
Zahedan & $39(10.6)$ \\
Zabol & $34(9.2)$ \\
Khash & $47(12.7)$ \\
Chabahar & $27(7.3)$ \\
Iranshahr & $71(19.2)$ \\
Saravan & $115(31.2)$ \\
Nikshahr & $36(9.8)$ \\
\hline
\end{tabular}

\footnotetext{
${ }^{\mathrm{a}}$ Data are presented as No.(\%).
}

Table 2. Methods, Places, Temporal Variation of Suicides and the Outcome of the Suicide Patients Admitted to Zahedan KhatamAl-Anbia Hospital, 2010-2012 $(\mathrm{n}=369)^{\mathrm{a}}$

\begin{tabular}{|c|c|}
\hline & Results \\
\hline \multicolumn{2}{|l|}{ Methods } \\
\hline Drug & $88(23.8)$ \\
\hline Self-inflicted injury & $38(10.3)$ \\
\hline Toxins & $41(11.1)$ \\
\hline Burning & $197(53.4)$ \\
\hline Other methods & $5(1.4)$ \\
\hline \multicolumn{2}{|l|}{ Substances } \\
\hline Kerosene & $160(81.2)$ \\
\hline Petroleum & $12(6.1)$ \\
\hline Gas & $25(12.7)$ \\
\hline \multicolumn{2}{|l|}{ Place } \\
\hline Home & $325(88.1)$ \\
\hline Work place & $9(2.4)$ \\
\hline Relatives' place & $30(8.1)$ \\
\hline Public places & $5(1.4)$ \\
\hline \multicolumn{2}{|l|}{ Time of day } \\
\hline Morning & $132(35.8)$ \\
\hline Noon & $185(50.1)$ \\
\hline Night & $52(14.1)$ \\
\hline \multicolumn{2}{|l|}{ Time of Month } \\
\hline First half & $229(62.1)$ \\
\hline Second half & $140(37.9)$ \\
\hline \multicolumn{2}{|l|}{ Season } \\
\hline Spring & $127(34.4)$ \\
\hline Summer & $96(26.1)$ \\
\hline Autumn & $106(28.7)$ \\
\hline Winter & $40(10.8)$ \\
\hline \multicolumn{2}{|l|}{ Hospitalization, day } \\
\hline$\leq 1$ & $145(39.3)$ \\
\hline $2-4$ & $192(52.0)$ \\
\hline$\geq 5$ & $32(8.7)$ \\
\hline
\end{tabular}

for $35.8 \%$ and $14.1 \%$ of the subjects, respectively. In terms of the time of the month, suicide was more likely to occur during the first half of the month (62.1\% versus $37.9 \%$ that took place during the second half of the month). One third of suicide cases were reported during spring (March to May) followed by autumn (September to November) (28.7\%) and summer (June to August) (26\%) and suicide was less likely to happen during the winter (December to February). Almost half of the cases were admitted to hospital for 2-4 days and 39.3\% were hospitalized for a day or less. Only $8.7 \%$ of the cases were admitted to hospital for 5 days or more. Overall, $49.6 \%$ of the suicide 
cases were fatal and 50.4\% survived the suicide attempt.

The precipitating factors associated with suicide have been illustrated in the Figure 1. Spouse violence and dispute accounted for half of the suicide cases. The second cause of suicide was drug abuse (18\%). Family fanaticism and conflict together accounted for $15 \%$ of the cases. Unemployment and the stressful life events were reported as $7 \%$ and $6 \%$ of the causes of suicide, respectively.

Comparing the precipitating factors between male and female cases (Table 3), showed that all factors were more common in females except for drug abuse that was more frequent in male subjects attempting suicide (64.6\% in males versus $35.4 \%$ in female). The differences in the proportion of the factors were statistically significant (P value for Fisher's exact test $<0.0001$ ).

Fatal and non-fatal suicide cases have been compared by socio-demographic and suicide attempt characteristics in Table 4. The suicide patients who died were more likely to have a poor income as compared with those subjects who survived (59.3\% versus $40.7 \%$ ) and a greater proportion of cases with medium or good income were among those who were discharged from hospital after a suicide attempt. The difference was statistically significant $(\mathrm{P}<$ 0.017). Patients who committed suicide during spring were more likely to survive (59.1\% versus $40.9 \%$ ) and a greater percentage of fatal outcomes (61.5\% versus 38.55 ) were observed among those attempted suicides that occurred during summer time and the differences were statistically significant with a $\mathrm{P}<0.026$. When comparing the methods used for suicide between fatal and non-fatal cases, a statistically significant difference was identified between the two groups $(\mathrm{P}<0.0001)$. More than $88 \%$ of the cases who used burning as a method of suicide succumbed, while those who used other methods such as drug ingestion or self-inflicted injury were more likely to survive the suicide attempts.

Table 3. Distribution of Factors Associated with Suicide Attempts by Gender in Patients Admitted to Zahedan Khatam-Al-Anbia Hospital, 2010-2012

\begin{tabular}{lccc}
\hline & Female & Male & P Value \\
\hline Spouse'violence & $94(73.4)$ & $34(26.6)$ & $<0.0001$ \\
Spouse dispute & $47(83.9)$ & $9(16.1)$ & - \\
Drug abuse & $23(35.4)$ & $42(64.6)$ & - \\
Family fanaticism & $23(69.7)$ & $10(30.3)$ & - \\
Family conflict & $12(52.2)$ & $11(47.8)$ & - \\
Recent stressful life events & $15(62.5)$ & $9(37.5)$ & - \\
Unemployment & $18(66.7)$ & $9(33.3)$ & - \\
\hline Other factors & $8(61.5)$ & $5(38.5)$ & - \\
\hline
\end{tabular}

${ }^{\mathrm{a}}$ Data are presented as No. (\%).

Table 4 . Factors Associated with Fatal Suicide Outcome in Patients Admitted to Zahedan Khatam-Al-Anbia Hospital, 2010-2012 a

\begin{tabular}{|c|c|c|c|}
\hline & Discharged & Died & P Value \\
\hline Gender & & & 0.188 \\
\hline Female & $127(52.9)$ & $113(47.1)$ & \\
\hline Male & $59(45.7)$ & $70(54.3)$ & \\
\hline Age, y & & & 0.968 \\
\hline$\leq 15$ & $31(51.7)$ & $29(48.3)$ & \\
\hline $16-25$ & $79(49.4)$ & $81(50.6)$ & \\
\hline $26-34$ & $51(50.0)$ & $51(50.0)$ & \\
\hline$>34$ & $25(53.2)$ & $22(46.8)$ & \\
\hline Occupation & & & 0.141 \\
\hline Housewife & $104(50.5)$ & $102(49.5)$ & \\
\hline Government job & $22(68.8)$ & $10(31.2)$ & \\
\hline Self-employed & $37(45.1)$ & $45(54.9)$ & \\
\hline Unemployed & $23(46.9)$ & $26(53.1)$ & \\
\hline Education & & & 0.984 \\
\hline Illiterate & $40(51.9)$ & $37(48.1)$ & \\
\hline
\end{tabular}


Behmanehsh Pour F et al.

\begin{tabular}{|c|c|c|c|}
\hline Primary school & $91(50.6)$ & $89(49.4)$ & \\
\hline Guidance and high school & $38(49.4)$ & $39(50.6)$ & \\
\hline Diploma and higher degrees & $17(48.6)$ & $18(51.4)$ & \\
\hline Place of Suicide & & & 0.592 \\
\hline Home & $166(51.1)$ & $159(49)$ & \\
\hline Work place & $3(33.3)$ & $6(66.7)$ & \\
\hline Relatives' place & $15(50.0)$ & $15(50.0)$ & \\
\hline Public places & $2(40.0)$ & $3(60.0)$ & \\
\hline Precipitating Factors & & & 0.065 \\
\hline Spouses' violence & $68(53.1)$ & $60(46.9)$ & \\
\hline Spouse dispute & $31(55.4)$ & $25(44.6)$ & \\
\hline Drug abuse & $25(38.5)$ & $40(61.5)$ & \\
\hline Family fanaticism & $14(60.9)$ & $9(39.1)$ & \\
\hline Family conflict & $10(30.3)$ & $23(69.7)$ & \\
\hline Recent stressful life events & $15(62.5)$ & $9(37.5)$ & \\
\hline Unemployment & $16(59.3)$ & $11(40.7)$ & \\
\hline Marital Status & & & 0.668 \\
\hline Married & $118(49.4)$ & $121(50.6)$ & \\
\hline Single & $39(51.3)$ & $37(48.7)$ & \\
\hline Divorced & $18(48.6)$ & $19(51.4)$ & \\
\hline Widowed & $11(64.7)$ & $6(35.3)$ & \\
\hline Income & & & 0.017 \\
\hline Poor & $46(40.7)$ & $67(59.3)$ & \\
\hline Medium & $103(52.3)$ & $94(47.7)$ & \\
\hline Good & $37(62.7)$ & $22(37.3)$ & \\
\hline History of mental disorders & & & 0.396 \\
\hline Hospitalized & $17(41.5)$ & $24(58.5)$ & \\
\hline Outpatient & $117(50.4)$ & $115(49.6)$ & \\
\hline None & $52(54.2)$ & $44(45.8)$ & \\
\hline Time of suicide & & & 0.07 \\
\hline Morning & $66(50.0)$ & $66(50.0)$ & \\
\hline Noon & $101(54.6)$ & $84(45.4)$ & \\
\hline Night & $19(36.5)$ & $33(63.5)$ & \\
\hline Suicide methods & & & $<0.0001$ \\
\hline Drugs & $83(94.3)$ & $5(5.7)$ & \\
\hline Self-inflicted injury & $38(100.0)$ & $0(0.0)$ & \\
\hline Toxins & $39(95.1)$ & $2(4.9)$ & \\
\hline Burning & $22(11.2)$ & $175(88.8)$ & \\
\hline Other methods & $4(80.0)$ & $1(20.0)$ & \\
\hline Season & & & 0.026 \\
\hline Spring & $75(59.1)$ & $52(40.9)$ & \\
\hline Summer & $37(38.5)$ & $59(61.5)$ & \\
\hline Autumn & $53(50.0)$ & $53(50.0)$ & \\
\hline Winter & $21(52.5)$ & $19(47.5)$ & \\
\hline
\end{tabular}




\section{Discussion}

The purpose of this study was to investigate the epidemiology of suicide and associated risk factors in suicide cases admitted to the emergency department of Zahedan Khatam-Al-Anbia Hospital. The results ofthis study showed that the majority of cases were young women with the low education levels, low income and more than three quarter of the cases had a history of mental disorders. The method most frequently used for suicide was burning and the majority of cases committed suicide at home and most likely at noon time. Almost one third of the cases occurred during spring time and half of the cases were fatal. Spouse violence and dispute accounted for half of the suicide cases followed by drug abuse.

Although suicide is a complex human behavior, a range of socio-demographic factors has been shown to be associated with an increased risk of suicidal behavior in different social and cultural settings. More than $40 \%$ of suicide cases in this study were in the age group of 16 to 25 years. This is consistent with the findings of similar studies from Iran $(6,11-13)$ and other countries $(14,15)$, in majority of which it has been reported that younger subjects account for a greater proportion of suicide cases. Study of the global patterns of mortality in young people has shown that suicide is the second leading cause of death in the 15-19 years age group (16). Analysis of data from studies on suicide attempts carried out in the Islamic Republic of Iran between 1981 to 2007 showed that the mean age of suicide attempters was 25 years (12). A study of suicide attempts in Hamedan province reported that the suicide attempt rate was highest in the age group of 15-24 years with an incidence rate of 536 cases per 100000 population (6). Similarly, more than $66.2 \%$ of the suicide cases admitted to the emergency department of a hospital were between 16 to 25 years old (13). The results from another study showed that the mean age of the suicide cases was 19 years for men and 24 years for women (11).

Suicidal behaviors in young people are thought to be linked to adverse life events and a wide range of risk factors have been identified (17). These include: social and educational disadvantages; childhood and family adversity; psychopathology; individual and personal vulnerabilities; exposure to the stressful life events and circumstances; and social, cultural and contextual factors.

Almost half of the suicide cases in our study were a result of family conflicts, with spouse violence accounting for more than a third of the total suicide events. Most common stressful life events that immediately precede the suicide attempts are the interpersonal conflicts mostly linked to relationships with spouses or partners (18). Suicidal behaviors are one of the major contributors to the global burden of disease among women. Evidence from the WHO multi-country study on women's health and domestic violence against women has shown that events such as intimate partner violence(IPV), non-partner physical violence, ever being divorced, separated or widowed, childhood sex- ual abuse and having a mother who had experienced IVP were the most consistent risk factors for suicide attempts in women(19). In a study of the socio-cultural contexts of suicide attempts among women in Iran, family conflicts, marriage and love, social stigma, pressure of high expectations, and poverty were the main issues identified as the suicide precipitating factors in women (20).

Exposure to intimate partner violence is an event that is experienced by women living in low- and middleincome countries on a daily basis, being reported by $15 \%-71 \%$ of women over their lifetime (21). There is an evidence of a consistently strong relationship between the intimate partner abuse and suicide attempts in women (19). Another study has found that the physical violence to be associated with more than a four-fold increase in suicidal thoughts in women (22). Surprisingly, only $27 \%$ of the women subjected to spouse violence would disclose this to anyone (22), and they are less likely to seek medical advice (19).

A disrupted family environment and parent-adolescent conflict have been found to be associated with the suicide attempts (23). There is some evidence that the negative relationships with either or both parents significantly increase the risk of suicide and/or depression (24). In our study, a total of $15 \%$ of the suicide cases were a result of parent-adolescent conflicts and family fanaticism that put them at an increased risk of suicidal behavior. The results from a systemic review of social factors associated with suicide attempts in Iran showed that the family conflicts was the most frequent cause of suicide with an average prevalence of $32 \%$ (25). The prevalence in the studies reviewed ranged from $55 \%$ that was reported from Gilan province to $12 \%$ that was observed in Khorasan Razavi province. Moreover, the overall prevalence of marital problems was found to be $26 \%$. A study of the self-poisoning suicide attempts among students showed that $21.08 \%$ of the subjects had a history of child abuse and 22.5\% came from a broken family (26). A quarrel with a family member, a relative, and/or a friend was also found to be the most common precipitating factor $(74.4 \%)$ for suicide attempts by burning (27). Another study reported that almost half of suicide attempts was a results of family conflict (28). On the other hand, giving credit to the importance of the family appears to be associated with lower levels of parent-adolescent conflict, hence protecting the younger generation from suicide attempts. In comparison with disrupted family environments, adolescents living in an atmosphere of high family cohesion and low conflict are significantly less likely to attempt suicide (23).

We found seasonal variations in suicide attempts. This is consistent with studies from western countries (29, $30)$ and also some studies from Iran $(6,31-33)$. An Iranian study of the suicide cases from 2006 to 2010 across the country showed that the completed suicides were more likely to happen in summer and they were least prevalent in winter (32). However, in some studies, the clear pattern of seasonality has been identified for only 
suicides committed by the violent methods (29). As compared with females, the relationship between seasonal factors and violent suicides has been found to be stronger in male suicides (29). There are some evidence of the relationship between season and changes in human mood (34). This could be partly explained by the seasonal factors including daily sunshine and global radiation that influence the regulation of the serotonergic transmission and serotonin-1A receptor binding in limbic regions of the brain (35).

Other socio-demographic factors related to suicidal behavior include the economic constrains and educational failure. In this study, a greater proportion of the suicide cases had a poor or medium income and those with low income were more likely to die when attempting suicide. This is in agreement with the results from a systemic review of studies on suicide in Iran that estimated that $12 \%$ of the suicide attempts were linked to economic constrains, ranging from $4 \%$ to $40 \%$ in different studies (25).

One fifth of cases investigated in this study had no education and the educational level of almost half of them was primary school. This is comparable with the proportions reported in studies carried out in other parts of Iran $(13,36)$. In a survey of suicide by burning in Tehran, for instance, $26.2 \%$ of the cases were illiterate (33). However, in some studies people with high school and higher educational levels dominated the suicide cases (11). Moreover, in a systemic review of suicide studies in Iran, the prevalence of educational failure among cases with suicide attempts on average was found to be $5 \%(25)$.

Overall, $18 \%$ of the suicide cases in this study were related to drug abuse. This is in agreement with the findings from similar studies conducted in Kerman and Hamadan provinces that the proportions of drug abuse in the suicide cases admitted to the emergency department were16\% and $16.3 \%$, respectively $(11,28)$. The relationship between drug abuse and suicide attempts could be partly explained by what is called "interpersonal theory" (37). According to the theory, the repeated exposure to physically painful experiences such as injecting drugs leads to pain habituation, which is likely to entail the suicidal behavior. Harmful behaviors including suicide in people who are suffering from drug abuse is a common finding (38). There is some evidence that the strength of association between drug abuse and suicidal acts depends on the type of the substance abused, with prescription drug abuse showing the strongest influence, followed by inhalant and cannabis abuse (39). Moreover, it has been identified that subjects with the recent drug use are approximately 5 times more likely to use violent suicide methods as compared with those who did not report substance abuse (40).

It has been hypothesized that the individuals who attempt suicide differ from those who complete suicide. In the present study, we compared these two groups in terms of socio-demographic and suicide-related characteristics. In a review of suicide data for the time period from March 2001 to March 2007 that were retrieved from health system databases of 41 Iranian medical universities, the prevalence of the completed suicides was $7.3 \%$, which is much lower than what we observed in our study (41). Moreover, a wide range of variations in the prevalence of case fatality among suicide cases across the country has been shown, changing between $2 \%$ and $25.3 \%$ (11, $13,28,42)$. Given the fact that more than $90 \%$ of the cases included in this study were those who were referred from other districts and hence more likely to suffer from lifethreatening complications that made them eligible for referral to more advanced and equipped centers at the provincial level, over-representation of those cases is most likely to have resulted in more fatal cases as compared with figures from different studies across the country. This was further substantiated by comparing burning (the most fatal method) with the non-burning suicide methods between the districts. For instance, $70 \%$ and $65 \%$ of the cases referred from Chabahar and Saravan districts used burning for a suicide act, which was more likely to succumb in spite of referral to an advanced center.

Low income, suicide attempts during summer time, and burning used as a method of suicide were more likely to be associated with fatal outcomes. We did not identify any gender differences in terms of suicide outcome, some studies have found a significant relationship between gender and fatal suicide (7). The results from our study showed that suicide by burning was the most common method used in the completed suicide cases. However, in studies from different geographical regions of Iran a wide range of violent and non-violent methods are used, which seems to be influenced by the social and cultural context of the communities. For instance, a study on the case fatality rate of the different suicide methods in Ilam province showed that the most common suicide methods in fatal cases were hanging (75.4\%) and self-immolation (68.3\%), and the least fatal methods were drug ingestion and cutting (42).

One of the limitations of this study was representativeness of the data used for analysis, as we used the information from only one referral hospital HIS and Forensic Medicine Department data. However, this hospital is a known burn and toxicology center and the suicide cases are more likely to be admitted to this hospital and only a small fraction of cases are admitted to other hospitals.

Suicide is a multi-factorial public health problem which results from an interaction between a wide range of demographic, social and cultural factors. Identifying the potential contributing factors and incorporating them into all preventive programs can help the public health authorities and policy-makers to mitigate the suicidal behaviors within communities.

\section{Acknowledgements}

Authors would like to express their sincere appreciation to the head of Zahedan Khatam-Al-Anbia Hospital and also to Mrs. Touzandejani, a burns ward nurse andthe emergency department staff who helped us with data 
collection. We are also thankful to all patients and their families who participated in this study.

\section{Authors' Contributions}

Fateme Behmanesh Pour planned the study design, and coordinated the conduct of the study. She also collected the study data and participated in drafting of the manuscript; Seyed Mehdi Tabatabaei, carried out the statistical analysis and interpretation of the data and drafted this paper; Nour-Mohammad Bakhshani, provided the technical counseling on study design and critically revised the manuscript.

\section{Funding/Support}

This study was supported by Zahedan University of Medical Sciences, Zahedan, IR Iran.

\section{References}

1. World Health Organization. Suicide prevention (SUPRE). WHO: Geneva; 2014.

2. Varnik P. Suicide in the world. Int J Environ Res Public Health. 2012;9(3):760-71

3. WHO. Public health action for the prevention of suicide: A framework.Geneva, Switzerland: World Health Organization; 2012.

4. World Health Organization . Suicide.: EMRO; 2014. Available from: http://www.emro.who.int/health-topics/suicide/index. html.

5. Ghoreishi SA, Mousavinasab N. Systematic review of researches on suicide and suicide attempt in Iran. Ir J Psychiatry Clin Psychol. 2008;14(2):115-21.

6. Ghaleiha A, Afzali S, Bazyar M, Khorsand F, Torabian S. Characteristics of hospitalized patients following suicide attempt in hamadan district, iran. Oman Med J. 2012;27(4):304-9.

7. Najafi F, Hasanzadeh J, Moradinazar M, Faramarzi H, Nematollahi A. An epidemiological survey of the suicide incidence trends in the southwest iran: 2004-2009. Int J Health Policy Manag. 2013;1(3):219-22.

8. Naghavi M, Shahraz S, Sepanlou SG, Dicker D, Naghavi P, Pourmalek F, et al. Health transition in Iran toward chronic diseases based on results of Global Burden of Disease 2010. Arch Iran Med. 2014;17(5):321-35.

9. Isometsa E. Suicidal behaviour in mood disorders--who, when, and why? Can J Psychiatry. 2014;59(3):120-30.

10. Wasserman D. A stress-vulnerability model and the development of the suicidal process. In: Wasserman D editor. Suicide: An unnecessary death. London: Martin Dunitz; 2001

11. Zohor AR, Torabi M, Pasandeh H. Epidemiology of suicide in referring to emergency center of center of jiroft of Kerman. OFOGH-E-DANESH. 2001.

12. Ghafarian Shirazi HR, Hosseini M, Zoladl M, Malekzadeh M, Momeninejad M, Noorian K, et al. Suicide in the Islamic Republic of Iran: an integrated analysis from 1981 to 2007.EMHJ.2000;18(6).

13. Mohammadi GH, Saadaty A. Survey of epidemiology and etiology of suicidal attempt and relation to socio demographic factors in the administrated emergency unit Central Hospital of Neishabur in 2003. Q J Fundam Mental Health. 2004:23-4.

14. Alvarado-Esquivel C, Sánchez-Anguiano LF, Arnaud-Gil CA, Hernández-Tinoco J, Molina-Espinoza LF, Rábago-Sánchez E. Socio-Demographic, Clinical and Behavioral Characteristics Associated with a History of Suicide Attempts among Psychiatric Outpatients: A Case Control Study in a Northern Mexican City. International journal of biomedical science: IJBS. 2014;10(1):61.

15. Kim DR, Ali M, Thiem VD, Wierzba TF. Socio-ecological risk fac- tors for prime-age adult death in two coastal areas of Vietnam. PLoS One. 2014;9(2).

16. Patton GC, Coffey C, Sawyer SM, Viner RM, Haller DM, Bose K, et al. Global patterns of mortality in young people: a systematic analysis of population health data. Lancet. 2009;374(9693):88192.

17. Beautrais AL. Risk factors for suicide and attempted suicide among young people. Aust N Z J Psychiatry. 2000;34(3):420-36.

18. Kubiak M, Musikowska B, Sein Anand J. [Recent life events preceding suicide attempt by drug overdose]. Przegl Lek. 2013; 70(8):551-4.

19. Devries K, Watts C, Yoshihama M, Kiss L, Schraiber LB, Deyessa $\mathrm{N}$, et al. Violence against women is strongly associated with suicide attempts: evidence from the WHO multi-country study on women's health and domestic violence against women. Soc Sc Med. 2011:73(1):79-86.

20. Keyvanara M, Haghshenas A. The sociocultural contexts of attempting suicide among women in Iran. Health Care Women Int 2010;31(9):771-83.

21. Garcia-Moreno C, Watts C. Violence against women: an urgent public health priority. Bull World Health Organ. 2011;89(1):2.

22. Ali TS, Mogren I, Krantz G. Intimate partner violence and mental health effects: A population-based study among married women in Karachi, Pakistan. Int J Behav Med. 2013;20(1):131-9.

23. Pena JB, Kuhlberg JA, Zayas LH, Baumann AA, Gulbas L, Hausmann-Stabile C, et al. Familism, family environment, and suicide attempts among Latina youth. Suicide Life Threat Behav. 2011;41(3):330-41.

24. Consoli A, Peyre H, Speranza M, Hassler C, Falissard B, Touchette $\mathrm{E}$, et al. Suicidal behaviors in depressed adolescents: role of perceived relationships in the family. Child Adolesc Psychiatry Ment Health. 2013;7(1):8.

25. Nazarzadeh M, Bidel Z, Ayubi E, Asadollahi K, Carson KV Sayehmiri K. Determination of the social related factors of suicide in Iran: a systematic review and meta-analysis. BMC Public Health. 2013;13:4

26. Farzaneh E, Mehrpour O, Alfred S, Moghaddam HH, Behnoush $\mathrm{B}$, Seghatoleslam T. Self-poisoning suicide attempts among students in Tehran, Iran. Psychiatr Danub. 2010;22(1):34-8.

27. Lari AR, Alaghehbandan R, Panjeshahin MR, Joghataei MT Suicidal behavior by burns in the province of Fars, Iran. Crisis. 2009;30(2):98-101.

28. Amiri B, Pourreza A, Rahimi Foroushani A, Hosseini SM, Poorolajal J. Suicide and associated risk factors in hamadan province, west of iran, in 2008 and 2009. J Res Health Sci. 2012;12(2):88-92.

29. Preti A, Miotto P. Seasonality in suicides: the influence of suicide method, gender and age on suicide distribution in Italy Psychiatry Res. 1998;81(2):219-31.

30. Sisti D, Rocchi MB, Maccio A, Preti A. The epidemiology of homicide in Italy by season, day of the week and time of day. Med Sc Law. 2012;52(2):100-6.

31. Pajoumand A, Talaie H, Mahdavinejad A, Birang S, Zarei M Mehregan FF, et al. Suicide epidemiology and characteristics among young Iranians at poison ward, Loghman-Hakim Hospital (1997-2007). Arch Iran Med. 2012;15(4):210-3.

32. Shojaei A, Moradi S, Alaeddini F, Khodadoost M, Ghadirzadeh MR, Khademi A. The Association between Completed Suicides and Season of the Year in an Iranian Population. Iran J Public Health. 2013;42(3):293-7.

33. Taghaddosinejad F, Sheikhazadi A, Behnoush B, Reshadati J, Sabery SH. A survey of suicide by burning in Tehran, Iran. Acta Med Iran. 2010;48(4):266-72.

34. De Vriese SR, Christophe AB, Maes M. In humans, the seasonal variation in poly-unsaturated fatty acids is related to the seasonal variation in violent suicide and serotonergic markers of violent suicide. Prostaglandins Leukot Essent Fatty Acids 2004;71(1):13-8.

35. Spindelegger C, Stein P, Wadsak W, Fink M, Mitterhauser M, Moser U, et al. Light-dependent alteration of serotonin-1A receptor binding in cortical and subcortical limbic regions in the human brain. Biol Psychiatry. 2012;13(6):413-22. 
36. Keyvanara M, Mousavi SG, Karami Z. Social Class Status and Suicide Characteristics: A Survey among Patients Who Attempted Suicide in Isfahan. Mater Sociomed. 2013;25(1):56-9.

37. Van Orden KA, Witte TK, Cukrowicz KC, Braithwaite SR, Selby EA, Joiner TE, Jr. The interpersonal theory of suicide. Psychol Rev. 2010;117(2):575-600.

38. Mokhber N, Asgharipour N, Bananaj A. Frequency of harmful behaviors in patients who are suffering from substances abuse. Int J High Risk Behav Addict. 2012;1(3):132-6.

39. Kaley S, Mancino MJ, Messias E. Sadness, suicide, and drug misuse in Arkansas: results from the Youth Risk Behavior Survey
2011. J Ark Med Soc. 2014;110(9):185-6.

40. da Silveira DX, Fidalgo TM, Di Pietro M, Santos JG, Jr., Oliveira LQ. Is drug use related to the choice of potentially more harmful methods in suicide attempts? Subst Abuse. 2014;8:41-3.

41. Saberi-Zafaghandi MB, Hajebi A, Eskandarieh S, Ahmadzad-As M. Epidemiology of suicide and attempted suicide derived from the health system database in the Islamic Republic of Iran: 2001-2007. EMHJ. 2012;18(8).

42. Razaeian M, Sharifirad G. Case fatality rates of different suicide methods within Ilam province of Iran. J Educ Health Promot. 2012;1:44. 